\title{
Images that Speak: Delineating Nigeria's Modernity through the Graphic Configuration of Postage Stamps
}

\author{
Clement Emeka Akpang \\ School of Arts \& Design, University of Bedfordshire, United Kingdom \\ clementakpang@yahoo.com
}

\section{Doi:10.5901/mjss.2015.v6n4s2p47}

\section{Abstract}

\begin{abstract}
Images possess great visual power, because they embody contents which references varying aspects of a person, community or nations existence and history. Ancient civilizations have been constructed by analysing the visual configuration of images to uncover the historic consciousness of the period they where created. Contemporary discourse on the power of images has thus, embraced and emphasised gravity of images as a unique form of communication and medium of research. Postage stamps constitute one of such images with great visual powers; because it's designs reflect specific country designations. This paper focused on addressing one research question; how can the visual configuration of stamps be interrogated as visual reference to delineate the modernity of a nation? Adopting visual analysis as methodology of enquiry, this paper examined Nigerian postage stamps from the 1850s to this contemporary age to delineate her transmogrification from primitivism to modernity. Findings from this study led to the conclusion that, through analysis of the changes in stamp designs which very often is impelled by social, cultural, religious or political forces, the entirety of a nations development can be reconstructed, as postage stamps offer insights into paradigm shifts because they constitute a form of visual documentation of a nation's historic transformation. Through postage stamps as adopted in this paper, Nigeria's transmogrification into a modernity (modern state) is vividly delineated with the changes in designs found to be influenced by colonialism, nationalist activism, decolonization politics and Pan-Africanism.
\end{abstract}

Keywords: Modernity, Nigeria, Postage Stamps, Delineate, Visual Configuration, Images

\section{Introduction}

The power of objects and images and their gravity in historiographical studies are detailed in fields such as anthropology and the humanities, showing that the entirety of past civilizations can be constructed through the interrogation of objects and images in the context of their creation. The efficiency of such historiographical enquiries has been premised on culture specific meaning making through the reading of composition of artifacts and archeological finds excavated from varying historic sites (Orser 1996: 1). This reference to the field of archeology, is to construct a context of a field entirely successful in employing and revealing the power of ancient images; this thus, galvanizes the hypothesis that images, artifacts and found objects possesses distinct qualities as embodiments of content from whence meaning extensions can be deduced. As Eugene Kleinbauer succinctly opined in 'Modern Perspectives in Western Art History', "works of art and images are symbolic and can become that which they symbolize" (kleinbauer 1971: 7). Images and art objects therefore exist as semiotics of events, circumstances, peoples and places at different historic and contemporary contexts. This symbolism of images and objects can only be deciphered through a detailed interrogation of the visual configuration contained in such images or art objects. Douglas Harper writing on the symbolic power of images 'Talking about Pictures: a Case of Photo Elicitation' opined that, "images produces different kind of information, evokes feelings, and memories that are due to the photograph's or object's particular form of representation" (Harper 2002:24), likewise, Gunther Kress in 'The Grammar of Visual Design' corroborates this view point that because images or artifacts depicts places and things combined "in visual statements, they foster greater complexities and extension of meaning" (Kress and Leeuwen 1996: 10). It is evident therefore, that, meanings are extended because of the evoking powers of images since they contain certain vital semiotic codes, which elicit varying culture/civilization-specific meanings. To understand why images can elicit extended meanings or evoke certain emotions and feelings or enable the reconstruction of past civilizations as has been demonstrated by fields such as archeology, it suffices to first elucidate the power of images to provide a base for the hypothesis put forward in this paper. 


\subsection{The Power of Images}

An image is defined as a representation of the form of a person or thing in art, such as a painting or photograph. As a form of visual representation of something, images constitute broader categories as drawings, prints, stamps etc. Images possess varying visual powers, representational and even abstractly contemplative as forms of communication and visual connections. They constitute "a language in their own right, not simply a decorative adjunct to so-called true verballanguage....as the visual language of pictures can lead to meaning making" (Olshansky 2008: 16). In "The power of pictures: Creating Pathways to Literacy through Art', Beth Olshansky argued that images constitute a form of language on their own, capable of conveying meanings without text. This is because as the study of semiotics establishes, images and art forms (two or three-dimensional), constitute ideograms encoded with meaning as symbolism of things, people, places concepts or ideas. It is this codified form of documentation as eluded to by Olshansky, which accord images as reference objects, the power to communicate to not just a select culture but to even universal audiences.

While images form a coherent form of visual communication, they possess greater contextual powers beyond their role in visual semantics. The making of images, art forms etc., is elicited by varying inspirations (documentation, representation, symbolization, or externalization of abstract concepts) on this premise therefore, images constitute visual embodiments of events, circumstances, achievements, social concerns as well as religious aspirations. They exist as visual documentations of the historic context and consciousness when they are created, capturing the spirit of that age. According to Claire Harrison, it is unique in stressing that an image is not the result of a singular, isolated, creative activity, but is itself a social process. As such, its meaning is a negotiation between the producer and the viewer, reflecting their individual social/cultural/political beliefs, values, and attitudes (Harrison 2003: 57).

Harrison reckons images are products of social circumstances, and social processes, making them a reflection of the individual/people's social, political, cultural, religious, beliefs, values, attitudes and aspirations. It follows therefore that; they act as visual documentation of such aspects of a society or nation's existentialism. Images are capable of incorporating in both realistic, stylized and abstract expression, records of events and societal transformation for future reference for as Eugene Klieinbauer further opined, "works of art or images are immortal" because long after the civilizations that made them have left, such visual forms remain and through them the existence of long lost civilizations can be reconstructed. Another premier power of images is the ability to elicit responses from viewers. Because of the content of images (by content I refer to the visual configuration), they can stir up various responses, emotions, actions and thoughts amongst people. This power of eliciting varying levels of feelings and emotions in images is determined by "their themes, subject context and of their creation" (Freeberg 1991, Gregory 1994, Lomazzo 1584). On the impact of images in eliciting emotions and their ability to evoke even revolutionary consciousness, Halfmann and Young observed in 'War Pictures: The Grotesque as a Mobilizing Tactic', that,

Grotesque images can produce strong emotions that may increase the resonance of activist movement frames and provide physiological "evidence" of immorality. Such images may also produce confusion and ambiguity that deeply engages readers or viewers and potentially breaks frames...(Halfmann and Young 2010: 1).

What this alludes to is the fact that, the visual configuration of images possesses powers capable of influencing not just people's emotions, but their thought processes and actions. The depicted theme and subject matter is largely responsible for this effect as well as the composition (by which I mean the expressionism: subversive, subtle, contra posture effects) on the images, which can draw viewers and force them into contemplation or connection with an event, occurrence etc. This ability to create connections or draw viewers into contemplative meanings making through themes and subject matter, encapsulate one of the greatest powers of images.

This brief survey of theories espousing the power of images, establishes the certitude that, beyond decorative and aesthetic appeal, images posses strong visual powers and acts as powerful representational forms that elicit various responses from viewers impelling on them plethora of memories, thoughts and actions. Most importantly too, it is evident that as images capture the essence of historical context and societal circumstances, they constitute visual documentations of the spirit, consciousness and aspirations of the context and civilizations when and where they were made; on this premise, images become visual references through which the cosmology, development and history of a people can be constructed hence the rationale for this paper.

As postage stamps are a typology of such powerful images, this paper will explore the visual configuration of postage stamps in Nigeria from its inception in the 1850s and from its content, attempt to alienate the chronology of Nigeria's modernization through the ages, using such postage stamps as references to historical events, development (social, cultural, political and religious). Firstly, in the following section, a brief definition of postage stamp will be provided, followed by an account of the origin and development of digital postage stamps. This will be followed by a discourse and visual analysis of Nigerian postage stamps as the crux of this paper, exploring the visual configuration of such stamps as 
reference to delineate Nigeria's modernity; emphasis will be on the power of such images in constructing a coherent account of a nation's development as visual symbolism of modernity. Nigeria's transmogrification from primitivism to modernity, as well as cultural and nationalist political activism will be connected through the visuals on stamps. This paper will then conclude with a summary of findings attained from analyzing stamps as visual symbols and unique methodology of historiographical enquiry.

\section{History of Postage Stamps and Context}

A postage stamp is a small piece of paper that is purchased and displayed on an item of mail as evidence of payment postage (National Postage Museum n.d). Postage stamps come in rectangular shape although in the past, some have been issued in circular, triangular and pentagonal shapes. They are printed on special paper, show a national designation and a denomination value on the front and, have adhesive on the back. There are a plethora of stamps but the most commonly occurring stamps are definitive stamps (stamps used for everyday postage). The first postage stamps in use where the hand stamps made from wood or cork invented in the 1680s in London by William Dockwra and Robert Murray, founders of the London Penny Post (Lawrence 1995:1). Although many people such as Dr. John Gray, Samuel Forrester, Charles Whiting, Samuel Roberts, Francis Worrell Stevens, Ferdinand Egarter and Curry Gabriel Treffenberg etc., hold claims to the invention of stamps, but the inventor of modern postage paper stamps is Sir Rowland Hill whose ideas of 1937 led to the first adhesive postage stamp the penny black used in the United Kingdom in 1840. Sir Rowland Hill's invention sparked a worldwide adoption of postage stamps for instance, Switzerland 1843, Brazil 1843, United States 1845 etc., and by the 1860s stamps became commonplace.

To many people, postage stamps are just pieces of illustrated paper only worthy of it's function as official payment sign to enables the postage of letters from one place to the other. It is however proven that, the content of postage stamps hold far extensive meanings with regards to their visual configurations and themes in different countries the world over. In the 'Symbolism of Postage Stamps: A Source for the Historian', Donald Reid observed that postage stamps posses visual powers as coded forms of documentation and communication even adopted by governments; "postage stamps are excellent primary sources for the symbolic messages which governments seek to convey to their citizens and to the world" (Reid 1984: 223). Various studies corroborate this view point; Raento and Brunn in "Visualizing Finland: Postage Stamps as Political Messenger' argue that,

postage stamps are a very political, territorially grounded and yet overlooked part of visual culture...the mundane omnipresence of stamps gives them considerable nation-building power and...reading as political, socioculturally and territorially specific texts offers valuable insights into the evolution and outlook of the issuing state and the imagined community within its boundaries (Raento and Brunn 2005: 160)

Hugo Dobson in 'Japanese Postage Stamps', supports this argument, pointing out the power of postage stamps as visual semiotics adopted as "government instrumentalize tool of propaganda to promote their own political ends" (Dobson 2002: 22). This highlights the fact that postage stamps can not be dismissed as mere pieces of design paper with postage functionality alone because the visuals found on faces of stamps are defined by peculiar national designation with depicted subjects ranging from early portrayals of kings, queens and presidents to later depictions of historical events, comics, holiday themes, famous people and a wealth of other subjects; this is why historians and collectors have been drawn to philately (the study of stamps). Although stamp collecting and their study might be a hobby for some people, but it is a vital form of historical reference, as government-issued postage stamps and their mailing systems have always been involved with the history of nations. It is on this premise, interrogating images that speak by espousing the power contained in their (stamps) visual configurations that this paper is situated to unravel Nigeria's transmogrification from primitivism to contemporaneity through the visual documentations found on postage stamps from its inception in the 1850s.

\section{Postage Stamps and Nigerian Modernity}

In 1852 the postal service was established in Lagos by the British government to facilitate communication and the movement of documents and commodities to and fro the British colony, thus the first stamps to appear in the shores of Nigeria where issued in Lagos in 1852. From the 1850s upwards, stamps portraying Queen Victoria were issued until October 1902. In January 1904 a new design portraying King Edward VII was issued, and was later reissued with different watermarks in October 1905. From 1905 upwards, different kinds of designs began to appear on postage stamps with varying connotative imperatives and through which the historiography of the Nigeria can be reconstructed. The changes in incorporated visuals and design composition provide viable insights through which the political, cultural, 
social, economic and religious consciousness of designated historical context can be interrogated. In the reading of these postage stamps, a system of categorization into periods will be employed. This categorization is made based on the changes in design and visual configuration and the historical consciousness perceived to be responsible for such design alterations.

\subsection{0-1910 Nigerian Postage Stamps (References Colonial Oppression and Subjugation of the Colonized)}

From 1852 - 1910, the visual configuration of stamps used in Nigeria, exhibits distinct characteristics, which captures the conditions of colonialism, depicting the frosty relationship between Britain and the colony. During this period the graphic configuration of postage stamps issued in both the Northern and Southern protectorates of Nigeria, was dominated by portraits of the heads of the British imperial government (Heads of Queen Victoria, King Edward VII, etc.).

This incorporation of the portraits of the heads of the British government on postage stamps indicated clearly the domination and to a large extent the subjugation of the colony by the imperial West; from this visuals one deciphers the flaunting of imperial prowess over its subject and a demonstration of ownership of the colony by Britain. This visual imposition through the design layouts of stamps, shows the strategy adopted to facilitate colonization in which the West impose itself on the colonized as a superior power/civilization to whom the 'Other' must be submissive in order to gain a leeway to development and civilization. The absence of indigenous Nigerians, or any paraphernalia of their cultural existence on these stamps, demonstrates that during the late 1850s to the 1910s, the colony was under intense oppression and subjugation by the imperial powers with all forms of indigenous culture and traditional structure vehemently subverted. It also demonstrates Britain's early views about the peoples of Nigeria; their consideration of the colonized as inferior subjects who must be oppressed using even military force in order to facilitate colonization and the exploitation of the colony's human and material resources. King Edward VII, Queen Victoria, King George V etc., are prominent features on these stamps. This visual imposition references the fact that during this period, Nigeria in every respect, was totally under western colonial subjugation and that the West barely had humane consideration of the colonized besides the veiled politically inclined missionary propaganda forced on them as a result of the abolition of slave (see figure 1-2).

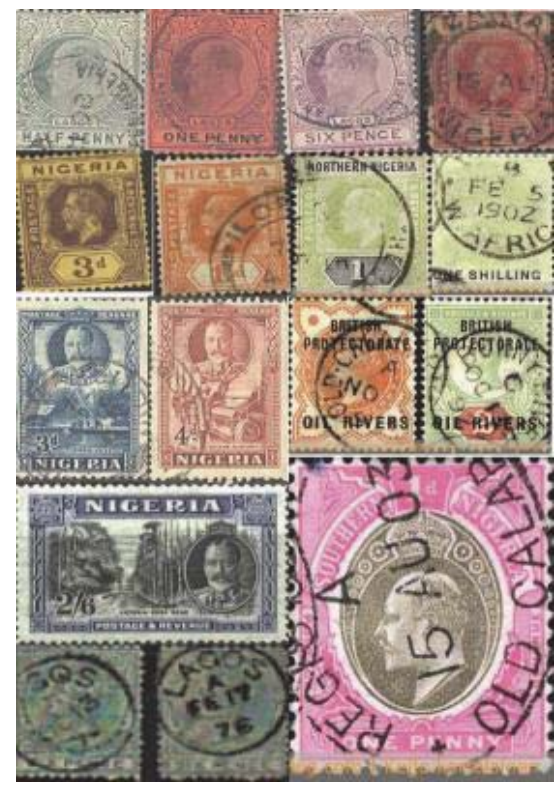

Figure 1: 1852-1910 stamps showing the dominant imposition of portraits of kings, queens and colonial officers, (flaunting of imperial prowess to subjugate the colonized 


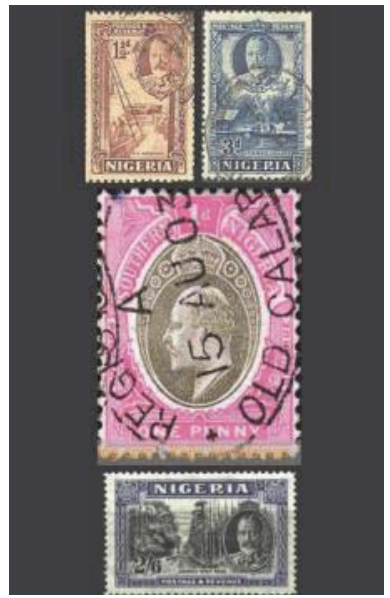

Figure 2: Close-up of 1852-1910 postage stamps in Nigeria (colonial domination)

The vital question is, what inspired and how influential was such visual imposition through these postage stamps? The rationale for this visual imposition and flaunting of imperial prowess is simple; during the period 1850-1910, British colonial administration faced fierce resistances from various ethnic groups and certain powerful Nigerian kings and such resistances hampered their exploitation of the colonies resources which led to the imperial government wedging warfare to dismantle such resistances (Colonial Reports 1901). They successfully overpowered and subverted various kingdoms in the region through military force, which they justified by branding 'expeditions'. Notably amongst such display of military prowess was, the Lagos bombardment of 1951, the Benin Expeditions of 1887, the ljebu Expedition of 1889 and the Aro Expedition of 1901. Thus, buoyed by their military successes at dismantling local resistance, the imposition of portraits of kings and queens on Nigerian postage stamps became a visual assertion of their dominance and reminder to the colonized of the prowess of the imperial military wherewithal. This explains the dominant imposition of the portraits of the heads of imperial government on visual forms in Nigeria as seen on these postage stamps; as Shearer West points out in 'Portraiture' portraits possesses great influential powers hence they have been deployed for centuries as a form of imposition of the powers of kings and queens and political tools to keep the governed in check as subjects to administrations and rulers (West 2004: 27). This entails therefore that, circulation of portraits of imperial powers and those in position of authority as was the case in the dominating appearance of queens and kings portraits the very heads of the imperial government, was intended to assert Britain's ownership of the colony, visually enforce obedience from subjects while celebrating the powers of those depicted in such images or visual forms. Nigerian postage stamps between 1850s-1910s, thus, clearly references a period in her history, characterized by domination, discrimination, imposition and subjugation of indigenous peoples by the West.

\subsection{0-1955 Nigerian Postage Stamps (References Rise of Indigenous Political and Nationalist Consciousness)}

Between 1910-1955, stamps exhibited remarkable changes in design and their visual configuration, as well as varying alterations to themes and subjects matter. Two major visual changes based on themes and subject matter surfaced and from such changes, one can decipher the historical context and consciousness when there were distributed; firstly the imposing portrait of the Queen reduced in proportion and in most cases only her crown was incorporated in design compositions; secondly, these postage stamps began incorporating Nigerian cultural themes that is, it began showcasing images of her topography, symbols of Nigerian culture and identity as well as captured in stylized symbolism the consciousness of the period. Based on these transformations in the visual configuration of the postage stamps between 1910-1955 a unique phase in Nigeria's modernity can be traced.

By analyzing the graphic configuration of these postage stamps, it is apparent that, certain political, economic and foreign cataclysmic forces etc. were responsible for the observed radical transformation in designs and themes. From 1900 the conglomeration of returnee Africans from Free Town, Brazil and other parts of Europe from their slavery sojourn as a result of the abolition of slave trade, who had returned in the 1860 s, as well as the rise of elite Nigerians trained in 
colonial schools and the West, and the rise of influential elite business men, led to the formation of powerful pressure groups in Lagos which began mounting varying levels of resistance to western oppression, and tailored discrimination of Africans. Pressure groups such as the 'People's Union' headed by Dr J K Randal midwifed various resistance activism in Nigeria for instance the Lagos strike, agitations against the exclusion of Africans in the Lagos Chamber of Commerce, the domination of whites in the Legislative Council and the conscious exclusion of educated elites from the council by the West. This rise of Nigerian elites, elicited within Nigerians the clamor for recognition on equal par with any other race as oppose to been treated by colonial administrations as mere uncivilized subjects. These elites and pressure groups mounted stiff opposition to what they considered oppressive and discriminating colonial policies and went further to send delegations to London to champion the fight against colonial racism demanding from the imperial government the recognition of Nigerians and better treatment of her peoples. During their activism in the west, leading Nigerian nationalist came in contact with Pan-African movements, which preached pride in the African self and identity as mode of resistance to inequality, which defined imperialism and colonialism.

A close interrogation of the visual configuration of theses stamps between $1900-1950$ s indicates clearly that such changes were influenced by indigenous agitations and the fact that such elite activism did lead to western renegotiation of its treatment of the colonized peoples of African not just Nigeria alone. One can see from these visuals that such local activism, as well as global Pan-Africanism, Nationalism and anti-slavery propaganda with strong influences from the Us and Paris, influenced the imperial government in Nigeria who began adopting a more accommodative approach to the governance of Nigeria, recognizing her land and peoples. These changes are captured in postage stamps as evinced by the appearance and incorporation of Nigerian landmass, cultural heritage and paraphernalia, juxtaposed with a reduced image of the Queens portrait or her crown (see figure 3). These postage stamps, therefore, captures and references this historical context documenting in visual form the political consciousness and paradigm shift which forced the West during this period to recognize the colonized and their land.

These postage stamps equally captured aspects Nigeria's modernity by which I mean the progression from the use of traditional institutions to the adoption of universal modern institutions and structures. During these period as can be read from these stamps, Nigeria experienced widespread transformations most significantly the boom in agricultural production (large-scale production of cocoa, cotton, rubber, palm oil etc.,) as main export commodities for the nation's growth development and stability. This was because, influenced by the Pan-African clamor for self-pride to facilitate decolonization, Nigeria elites encouraged agricultural production, which was promoted by the colonial regime to enable the sustenance of the nation as a self-reliant modern entity and these telling images effectively captured this matrix. Nigeria experienced widespread modern infrastructural developments, which reflected the establishment of varying modern strata of government, visually asserting the replacement of traditional structures of governance destroyed by colonial agency with modern structures as a variant of modernity; furtherance to this, as a result of economic boom, the Lagos railway established in 1898 with the Baro-Kano railway was amalgamated in 1912 and commuting made easy; crude oil was discovered and the first early refineries established; Nigeria had emerged as a modern nation and this is referenced in the symbolic images (graphic configurations) of these postage stamps (see figure 4 below).

Analyzing these postage stamps equally indicates a significant turn of events during this period; as a result of the advocacies of Nigerian leaders and nationalist at global events, there was more global recognition of Nigeria as an emerging modern state. Nigeria began engaging in global affairs making her voice heard; contributing to global issues as clearly visualized in the graphic configuration of these postage stamps between 1910-1955. It is overtly clear therefore, that these postage stamps hold in them key information of political activism which occasioned changes in the way Britain related with Nigeria and records of Nigeria's economic and infrastructural development and her engagement in globalism from this period; hence these stamps act as visual guide of the historiography of her modernism. 


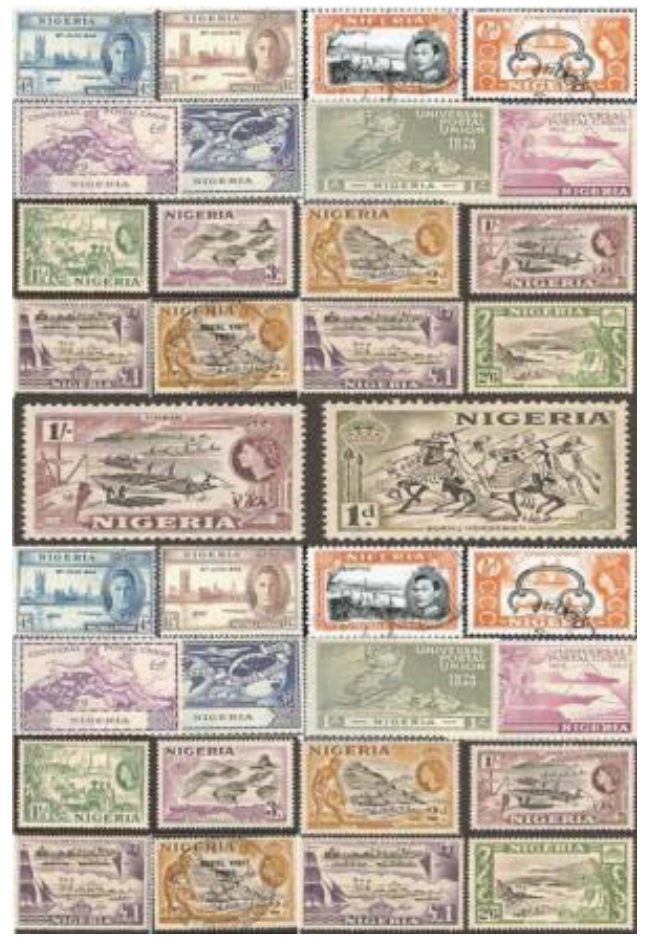

Figure 3: 1910-1955 postage stamps showing reduction in the imposition of the portraits of heads of imperial government on Nigeria and the incorporation of Nigerian cultural heritage and paraphernalia

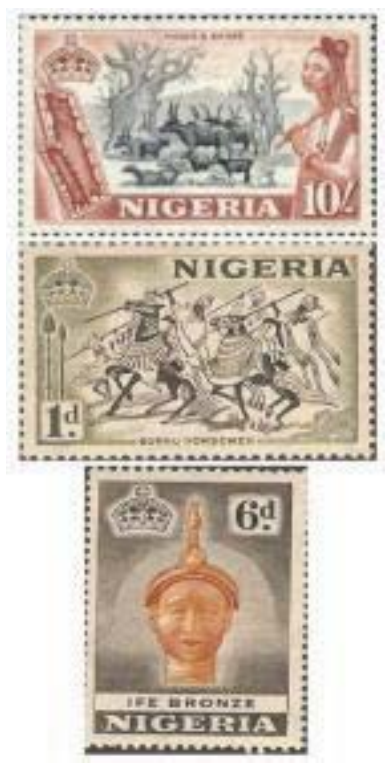

Figure 4: 1910-1955 close-up postage stamps indicating the celebration of Nigeria (advancement, identity, culture and aspirations) 


\subsection{5-1975 Nigerian Postage Stamps (References Political Resistance, Anti-colonialism, Rise of Nigerian Elites, Independence, Decolonization, and Globalism)}

1955s onwards, witnessed another dramatic changes to the graphic configurations of postage stamps, most notably was the complete disappearance of the portraits of the queen of England and head of the imperial government from the design of these stamps not even the symbolic queen's crown visible in the stamps of 1940s. Firstly there is in these postage stamps great emphasis on the nation, showcasing varying visuals esoterically Nigerian in identity, a form of celebration of Nigeria as a Nation. Imagery and ideographs of cultural heritages, Nigerian topography, and modern advancement etc., take up spaces in these postage stamps; spaces formally dominated by portraits of the queen and kings of England. The portraits of kings and queens or paraphernalia of imperial ownership were replaced with the portraits of elite Nigerians, politicians, and nationalist. This emphasis on the promotion of Nigeria as an emergent modern state, and promotion of Nigerians as modern elites on par with any other in the world, indicated shifting paradigms of power with the assumption positions of authority and control of the land by indigenes. Also evident on postage stamps from 1955-1975, their visual configurations captured various landmark events that had taken place nationally and internationally. Civil, social, military etc., events that had direct or indirect links and influence on the emergent Nigerian state are visualized on these stamps. Overtly, as these new designs indicate, the emphasis was on Nigeria, her people, development, aspirations and association with the wider union of nations.

This leaves the question begging as to what occasioned or warranted such radical creative and visual revolutions in the design of stamps during this period. The answer of course lies and can be deduced from the visuals of such stamps, which on closer examination serves as a window into the historical consciousness and that context in Nigerian history. The 1950s was the crescendo of Nationalism and Pan-Nigerian political and cultural activism with intense anticolonial, anti-European and decolonization advocacies spread across the country as Nigeria was on the verge of independence. Nationalism activism influenced by the doctrines of Pan-Africanism and Negritude, promulgated cultural revivalism and affirmation as modernist propaganda to facilitate resistance to the imposition of Western European culture and conventions on Nigeria (Africa) during the dark ages of colonization (Okeke-Agulu and Picton 2006: 26). In essence, promotion of indigenous culture (by culture I mean including its paraphernalia: identity, food, dresses, arts, dance, music, beliefs), was envisaged to subvert western oppression and subjugations in Africa as a whole; it was to serve as a visual statement of pride, of self-hood and a reminder that Africans had come of age and are and should be treated as equals with any other race in the world. It is apparent therefore, that the visual configurations of these stamps from 1955 in their incorporation and projection of Nigerian cultural forms, the Nigerian state, etc., resonate the political consciousness of the period in Africa's resolve to foster anti-Europeanism and anti-colonialism through the promotion of her culture and peoples. These stamps captured the political sensibilities of that historical context through their various incorporation of Nigerian cultural forms, they provide an aperture through which larger connections can be made of Nigeria's nationalist advocacies and as exhibited in this promotion of the doctrine and ideologies of Negritude, showcases Nigeria's connection with black consciousness movements throughout the world during that period.

The dominant incorporation of the portraits of African elites, intelligentsia and leading nationalist and most significantly their replacement of the portraits of Britain's Queens and Kings on these postage stamps, reveals a greater meaning when read in the context of the period; visually indicating a shift in power in colonial Nigeria during the 1950s. During this period especially towards late 1950s, Nigeria had worn the war against colonial oppression and subjugation through radical activism led by Nigerian nationalist who became the heroes of the nation and modernists championing the course of Nigeria's launch into postcolonial-selfhood. The portrayal of these elites in these postage stamps was a celebration of their victory against colonialism, against western domination and against cultural imposition in Nigeria. The visual configuration of these postage stamps therefore, showcases 1950s Nigeria's political consciousness, (celebration of indigenous nationalist victory in the fight for decolonization) and the role of the elites in the emerging modern state. These paradigm shift indicated in design changes reveals a remarkable shift in allegiances during that decade; as opposed to relying as subjects on Western imperial colonial powers, Nigerians began looking up to the nationalist and elites as leaders on which laid the responsibility of leading them upon the attainment of independence in 1960 into postcolonial self-hood. These postage stamps, capture clearly the overthrowing of the colonial regime in Nigeria and the fading of colonial grip with its subjugate policies on indigenous people and their country (see figures 5-9). 


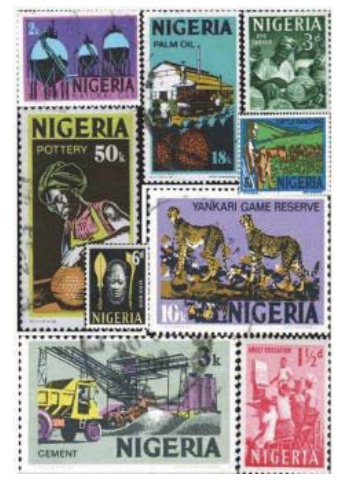

Figure 5: 1955-1975 Postage stamps celebrating of Nigerian identity, culture and modern development

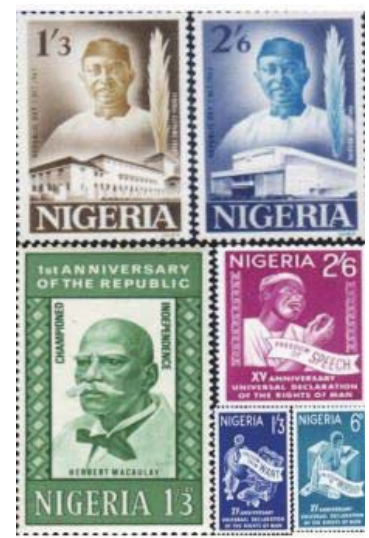

Figure 6: 1955-1975 Postage stamps: celebration of Nigerian elites, Nationalists and success in facilitating decolonization

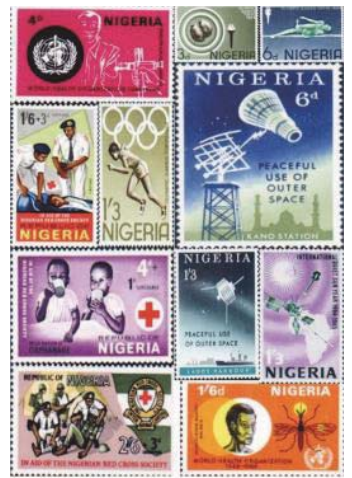

Figure 7: 1955-1975 Postage stamps: indication of Nigeria's involvement in global affairs beyond her shores, a variant of her modernity and record of Social events. 


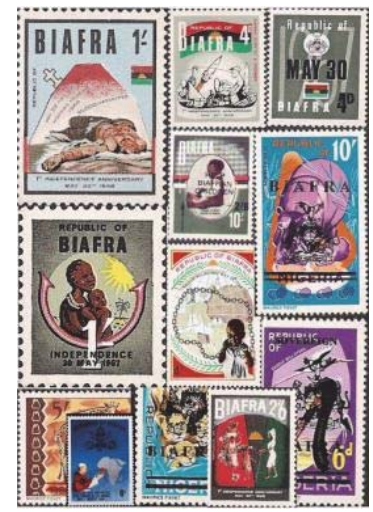

Figure 8: 1955-1975 Postage stamps: Recording social events - Capturing the dark ages of Nigerian civil war in the 1960s and exposing the adversities of the legacies of colonialism

Also, the stamps that appeared during this period, recorded national and international social issues relating to health, sports global concerns etc. These changes in design and the incorporation of themes beyond the shores of Nigeria clearly indicate that, from the 1960s onwards as Nigeria attained independence, she became part of a global community of nations and Nigeria was now concerned with social issues within and beyond her shores. This engagement in the affairs of the wider global world indicated a variant of modernity capturing Nigeria's modern civilization; the Tokyo 1964 Olympics, issues in the USA, space missions, and other global concerns etc., are captured in these postage stamps.

Most notable amongst issues visualized in these posters besides sports and health concerns, was the Nigerian civil war. The designs on the postage stamps during the 1960s provide references to the dark ages during that period; they capture the cruelty of war, destruction of lives and properties, and the suffering of the masses in Nigeria (see figure 9 above). These stamps paint poignant pictures of the divisibility; tribal allegiance, unrest, political skirmishes and more so the legacies of colonialism, which to a large extent was the cataclysmic, force that impelled the civil war. As aforementioned, reading into the visual configuration of these postage stamps of the 1960s, provide great insight into the unrest of the decade; clamor for authority, secession of part of the country as a result of national unrest, poor leadership at the center and also the fact that Nigeria's unity was already in danger, exposing the flaws of the system of governance imposed on Nigerians by fleeting imperial forces.

\subsection{5 - Contemporary Age}

The conceptual premise for postage stamp design set in place from the 1970s, dominated the graphic configuration of stamps from that decade and became a template upon which design layouts of stamps till date is based. From the late 1970s, stamps became more of records of social events, contemporary issues, celebration of political leaders and on rare occasions, celebration of the Nigerian state. This trend indicates a complete transformation from what was obtainable in the 1850s when the first stamps were distributed in Lagos. This indicates that, through a careful interrogation of the graphic visuals in stamps, as has been the crux of this research, the modernity and civilization of a nation state can be unveiled as is the case with Nigeria because design changes are largely impelled by social, political, cultural and economic circumstances.

\section{Conclusion}

Postage stamps as imagery contributes to the construction of national narratives, and such national narratives can only be constructed when stamps are "read as multilayered, identity-political texts in their time- and space-specific contexts" (Raento and Brunn 2008: 75). When this occurs, through postage stamps, the evolution of a state from primitivism to modernism, as well as the varying political and social relationships and activism/advocacies during a society's development can be reconstructed. This viewpoint is underpinned by the fact that, postage stamps constitute a vital art form symbolic as a medium of visual documentation of historical events/circumstances. Because of their national 
orientation, postage stamps can therefore delineate national histories, development, activism and consciousness through out the ages. In the context of the discourse on the power of images therefore, the interrogation of the graphic configuration of postage stamps can contribute to art and cultural scholarship since they extend meaning and evoke culture or nation-specific sentiments.

This paper explored the visual configuration of Nigerian postage stamps from the 1850s to the present age. The focus was to examine the changes in designs on such stamps as visual references or guide for alienating the evolution of Nigeria from her encounter with the West to this present age. This paper analysed the visual configuration of stamps in periodic historical contexts to recount issues relating to colonialism, nationalism cultural agitation, the rise of the colonial elites, Nigeria's emancipation and self-expression, which transpired during the nations' transmogrification from primitivism to modernity. By interrogating the transformations in designs and contents of composition layouts, a historic account of the development of Nigeria as a nation was constructed, with postage stamps acting as semiotic references.

This paper concludes that, in the discourse of the power of images, postage stamps constitute a great reference for such line of enquires because of its power to evoke historiography and enable the reconstruction of a nation's evolution through the ages, through the visual configurations of their designs. It is apparent from findings that, the designs on the faces of postage stamps, are symbolic visual documentation of historic circumstances, consciousness and development imbedded in representational, stylized or abstract forms to act as future visual references for a nations' history. Beyond the construction of past histories as this study has demonstrated in delineating Nigerian modernity, postage stamps can evoke varying responses and thought processes within the masses based on the themes and subjects referencing culture-specific national events and circumstances. Thus, this study contributes significantly to contemporary art discourse on interrogating images as a medium of research into history. Conclusively, this paper asserts that through themes and subjects captured in postage stamps, the cultural, religious, political, infrastructural, economic and social evolution of a nation can be delineated providing semiotic meanings extensions beyond other means of documentation.

\section{References}

Dobson, H. (2002, January). 'Japanese Postage Stamps: Propaganda and Decision aking'. Japan Forum (Vol. 14, No. 1, pp. 21-39). Taylor \& Francis.

Freedberg, D. (1991). The Power Of Images: Studies in the History And Theory of Response. University of Chicago Press. P1

Giessner, S. R., Ryan, M. K., Schubert, T. W., \& van Quaquebeke, N. (2011). 'The Power of Pictures: Vertical Picture Angles in Power Pictures'. Media Psychology, 14(4), 442-464.

Gregory, A. P. (1994). 'Powerful images': Responses to Portraits and the Political uses of Images in Rome. Journal of Roman Archaeology, 7, 80-99.

Halfmann, D., \& Young, M. P. (2010). 'War Pictures: The Grotesque as a Mobilizing Tactic'. Mobilization: An International Quarterly, 15(1), 1-24.

Harper, D. (2002). 'Talking about Pictures: A Case for Photo Elicitation'. Visual studies, 17(1), 13-26.

Harrison, C. (2003). 'Visual Social Semiotics: Understanding how Still Images make Meaning'. Technical communication, 50(1), 46-60.

Kleinbauer, W. E. (Ed.). (1971). Modern Perspectives in Western Art History: An Anthology of Twentieth-Century Writings on the Visual Arts (No. 25). University of Toronto Press.

Kress, G. R., \& Van Leeuwen, T. (1996). Reading Images: The Grammar of Visual Design. Psychology Press. p1

Lawrence, K. (1995) 'Before the Penny Black (First Series)'. Rec.Collecting.Stamps [Online] Accessed on 10th March 2015. Available at: http://norbyhus.dk/btpb.html

Lomazzo, G. P (1584) Trattato dell' arte Pittura, scultura, et architettura Milan

National Postal Museum: World's First Postage Stamps

Okeke-Agulu, C., \& Picton, J. (2006). 'Nationalism and the Rhetoric of Modernism in Nigeria: The Art of Uche Okeke and Demas Nwoko, 1960-1968:[With Commentary]'. African arts, 26-93.

Olshansky, B. (2008). The Power Of Pictures: Creating Pathways to Literacy Through Art, Grades K-6. John Wiley \& Sons. Pp.XII, XVI

Orser, C. E. (1996). A Historical Archaeology of the Modern World. Springer Science \& Business Media.

Raento, P., \& Brunn, S. D. (2005). 'Visualizing Finland: Postage Stamps as Political Messengers'. Geografiska Annaler: Series B, Human Geography, 87(2), 145-164.

Raento, P., \& Brunn, S. D. (2008). 'Picturing a Nation: Finland on Postage Stamps, 1917-2000'. National Identities, 10(1), 49-75.

Reid, D. M. (1984). 'The Symbolism of Postage Stamps: A Source for the Historian'. Journal of Contemporary History, $223-249$.

West, S. (2004). Portraiture. Oxford. Oxford University Press 